\title{
Relações de dominância entre as políticas fiscal e monetária: uma análise para economia brasileira no período de 2003 a 2009
}

\author{
Jevuks Matheus de Araújo ${ }^{1}$ \\ Cassio da Nóbrega Besarria ${ }^{2}$
}

\begin{abstract}
Resumo: O objetivo deste trabalho é verificar se a relação de dominância fiscal, verificada por Blanchard (2004), para economia brasileira no período de 1999 a 2003 permanece sendo válida para o período de 2003 a 2009. Especificamente, tem-se o propósito de identificar a existência de uma relação de longo prazo entre as séries, assim como, procurar alguma relação de repasse entre as políticas monetária e fiscal no curto prazo. Foram utilizados para compor a base de dados, informações do índice baseadas nos bônus (títulos de dívida) emitidos pelos países emergentes (EMBI+), informações do sistema eletrônico de liquidação e custódia (Selic), dívida líquida do setor público (\% PIB), índice da taxa de câmbio efetiva real e a necessidade de financiamento do setor público (NFSP). Para identificar a relação de longo prazo entre as séries, assim como, a relação de repasse entre as políticas monetária e fiscal no curto prazo foi utilizado o modelo (VECM). Os resultados mostraram que as políticas monetária e fiscal estão interligadas, como apontaram os coeficientes de ajuste de desequilíbrios longo prazo (vetor de co-integração) e que para o período analisado prevaleceu um regime de dominância monetária.
\end{abstract}

Palavras-Chave: Dominância Fiscal; Dominância Monetária; VECM.

JEL: H30, H62, E63

1 Professor da UFRPE Doutor em Economia. E-mail: jevuks@hotmail.com

2 Professor da UFPE Doutor em Economia. E-mail: cassiodanobrega@yahoo.com.br 


\title{
Dominance relationship between fiscal and monetary policy: an analysis for Brazilian economy in the period 2003 - 2009
}

\begin{abstract}
The objective of this work is to verify that the ratio of fiscal dominance, verified by Blanchard (2004), for the Brazilian economy in the period 1999 to 2003 remains valid for the period 2003 to 2009. Specifically, has the purpose of identifying the existence of a long-term relationship between the series, as well as look for any relationship between the transfer of monetary and fiscal policies in the short term. Were used to form the basis of data, index information based on bonds (debt securities) issued by emerging markets $(E M B I+)$, information from the electronic settlement and custody (Selic), net debt of the public sector (\% GDP) index of real effective exchange rate and the need for public sector borrowing (PSBR). To identify the long-term relationship between the series, as well as the relationship between the transfer of monetary and fiscal policies in the short term we used the model (VECM). The results showed that the monetary and fiscal policies are intertwined, as pointed out the adjustment coefficients of long-term imbalances (vector co-integration) and for the period analyzed prevailed a system of monetary dominance.
\end{abstract}

Key-Words: Fiscal Dominance; Monetary Dominance; VECM.

JEL Classification: H30, H62, E63

Introdução

Para compreender a relação entre política monetária e política fiscal no Brasil é preciso antes fazer um breve panorama da economia brasileira dos últimos anos. Com a implantação do plano real em 1994 a tão almejada estabilidade dos preços, que parecia não factível para economia brasileira, dava seus primeiros sinais de existência. No primeiro mandato do presidente Fernando Henrique Cardoso (1995 - 1998), a economia brasileira viveu sob a égide de um conjunto de políticas econômicas bastantes restritivas. Neste período, destaca-se a política de valorização cambial, o forte arrocho fiscal e as elevadas taxas de juros, todas estas medidas tinham como objetivo central manter a estabilidade dos preços na economia. 
No inicio do segundo governo de Fernando Henrique Cardoso (1999 - 2002) a economia brasileira sofria as conseqüências não apenas do excesso de políticas restritivas, mas também com as crises que ocorreram na Rússia (1998) e na Ásia (1997). No ano de 1999 alteram-se os mecanismos de controle da economia, adotam-se o regime câmbio flutuante e uma política monetária de metas de inflação. Desta forma, a taxa de juros se transforma no principal instrumento de controle do nível de preços da economia. Com a difícil tarefa de manter a inflação dentro da meta estabelecida, recorre-se a elevações na taxa de juros como forma de retrair a demanda e apreciar o câmbio via um influxo de capital.

No ano de 2002, com a iminência da eleição do candidato de esquerda, a economia brasileira passa por uma forte crise de confiança, instala-se tanto interna com externamente uma forte dúvida sobre a orientação das políticas econômicas que seriam adotas pelo provável governo de Luiz Inácio Lula da Silva. Entretanto, a única previsão que se estabeleceu foi a vitória de Lula, quanto às políticas adotadas estas surpreenderam positivamente o mercado e a confiança na economia brasileira foi restabelecida e fortalecida no primeiro Governo de Lula (2003 - 2006). Nesse período as políticas macroeconômicas foram efetivas o governo conseguiu manter a inflação dentro das metas estabelecidas e logrou bastante êxito na política externa.

No segundo mandato do presidente Lula (2007-2010), uma maior atenção é dada ao crescimento econômico. Em janeiro de 2007, foi lançado o Programa de Aceleração do Crescimento (PAC), a política fiscal do governo se torna mais expansiva. Com o objetivo de estimular a demanda agregada, o governo aumenta os gastos e investimentos públicos, bem como cria mecanismos para facilitar o crédito. Os resultados são alcançados e a economia brasileira volta a ter taxas significativas de crescimento, exceto pelo ano de 2009 onde o país sofreu as conseqüências da crise financeira de 2008.

Este panorama permite, de forma sintética, compreender a datação dos fatos, a qual servirá de respaldo para a análise das relações entre as políticas monetária e fiscal no Brasil. A questão a ser respondida é qual política se sobressai no cenário econômico onde além do controle do nível de preço, também se objetiva o crescimento econômico.

Diversos estudos sobre dominância fiscal e monetária têm sido realizados nos últimos anos. No clássico artigo de Sargent \& Wallace (1981), é analisado o efeito perverso de uma política fiscal sobre a política monetária, num contexto de dominância fiscal. Segundo esses autores, no regime de dominância monetária, a autoridade fiscal passiva gera um superávit primário que estabiliza a relação dívida/PIB de maneira que não é preciso que a autoridade monetária ativa monetize a dívida pública, sendo o controle do nível de preços dado pela demanda e oferta de moeda. Já no regime de dominância fiscal, a autoridade fiscal ativa gera um superávit primário independente da necessidade de estabilização da relação dívida/PIB, a autoridade monetária passiva perde 
o controle do nível de preços por precisar gerar as receitas de senhoriagem necessárias à solvência do governo.

Blanchard (2004), considerando uma economia aberta, uma proposição padrão é que a elevação da taxa de juros real torna mais atrativa a dívida pública e leva a uma apreciação real. No entanto, se a elevação da taxa de juros real também eleva a probabilidade de default da dívida, o efeito pode ser a dívida pública ser menos atraente e levar à depreciação real. Este resultado é mais provável quanto maior o nível inicial da dívida, quanto mais elevada a proporção da dívida denominada em moeda estrangeira e quanto mais alto o preço do risco.

O objetivo deste trabalho é verificar se a relação de dominância fiscal, verificada por Blanchard (2004), para economia brasileira no período de 1999 a 2003, permanece sendo válida para o período de 2003 a 2009. Especificamente, tem-se o propósito de identificar a existência de uma relação de longo prazo entre as séries, assim como, procurar alguma relação de repasse entre as políticas monetária e fiscal no curto prazo.

O trabalho está organizado em cinco seções, além desta introdução, temos na seção 2 uma revisão da literatura com alguns artigos importantes sobre o tema em estudo. Na seção 3, são descritos os procedimentos metodológicos adotados na pesquisa. Na seção 4, é realizada a discussão dos resultados obtidos pelas estimações e finalmente na seção 5 é apresentada a conclusão do trabalho.

\section{Revisão da literatura}

Nesta parte do trabalho serão apresentadas as acepções dadas ao conceito de dominância fiscal, sob o prisma do trabalho seminal de Sargent e Wallace (1981) e o desenvolvido por Blanchard (2004). Bem como a exposição dos resultados encontrados na literatura sobre a relação entre política fiscal e política monetária para economia brasileira.

O artigo de Sargent e Wallace (1981) nos remete a uma importante discussão sobre o arranjo das políticas monetária e fiscal, descrevendo os cenários de coordenação onde existe uma relação de dominância entre estas políticas. $\mathrm{O}$ propósito do trabalho foi demonstrar que mesmo em uma economia onde as hipóteses monetaristas são válidas, não é possível afirmar que a política monetária possa manter o controle permanente do nível de preços.

Segundo os autores, a política monetária consegue manter o controle do nível de preço em uma circunstância específica denominada de dominância monetária, onde a autoridade monetária define seu conjunto de políticas de 
forma independente, assim determinando o limite de receitas via senhoriagem. Como a receita via títulos públicos também é limitada pelo tamanho da economia, a autoridade fiscal deverá manter um superávit que mantenha constante a razão dívida líquida do setor público/PIB.

Por outro lado, a relação entre as políticas monetária e fiscal também pode ser caracterizada por uma situação de dominância fiscal, onde a autoridade fiscal define o tamanho do seu déficit independente da composição do orçamento. Estabelecendo assim, a quantidade de receita a ser originada via imposto inflacionário e vendas de títulos. Como a venda de títulos públicos possui um limite superior dado pelo tamanho da economia, resta ao país como forma de financiar a diferença entre receita e despesa o mecanismo de senhoriagem. Neste caso a política monetária não é capaz de manter o controle permanente da inflação, caracterizando-se assim um ambiente de dominância fiscal.

Segundo Blanchard (2004), em um cenário econômico onde as variáveis fiscais se encontram em uma situação não desejável, ou seja, onde exista uma elevada razão entre a dívida líquida do setor público pelo PIB (DLSP/PIB) e uma grande parte desta dívida em moeda estrangeira, uma política monetária restritiva é ineficiente. A conjuntura fiscal desfavorável associada à aversão ao risco dos investidores leva a ineficiência do controle de preços pela política monetária, representando, portanto, um tipo de dominância fiscal.

De acordo com a teoria tradicional, um acréscimo na taxa de juros possui dois canais de transmissão para o controle do nível de preço, o primeiro está associado à retração da demanda efetiva diminuindo o nível de investimento e o consumo privado e o segundo canal está vinculado ao câmbio, uma vez que uma elevação da taxa de juros aumenta a atratividade dos títulos públicos, culminando em uma maior entrada de capitais no país, por conseguinte fazendo com que o câmbio se aprecie influenciando positivamente o controle do nível de preços da economia.

No trabalho defendido por Blanchard (2004), no qual o autor analisa o segundo canal de transmissão da política monetária, os resultados esperados pela teoria tradicional não se concretizam, uma vez que os agentes são avessos ao risco e a elevação da taxa de juros implica um amento do tamanho da dívida, ou seja, aumenta o risco de default, fazendo com que haja uma saída de capital do país; assim, o fluxo de capital deve gerar uma depreciação e não uma apreciação do câmbio. Desta forma, os resultados são contrários ao defendido pela teoria tradicional.

$\mathrm{Na}$ análise empírica para economia brasileira no período de 1999 a 2003, Blanchard (2004) verificou a existência de dominância fiscal, onde a taxa de câmbio é influenciada positivamente pelo prêmio de risco e negativamente pelo diferencial da taxa de juros. Desta forma, os resultados confirmam a hipótese de que uma elevação da taxa de juros, na situação econômica em que se encontrava o Brasil naquele momento, possui um efeito contrário ao 
desejado pela autoridade monetária.

Após o trabalho de Blanchard (2004), o tema da dominância fiscal na economia brasileira passou a ser recorrente. Os principais resultados encontrados pelos trabalhos direcionam para não validação ${ }^{1}$ dos resultados observados pelo autor. Entretanto é importante destacar que o trabalho em questão se restringiu a um período muito especifico da economia brasileira. Nesta época o Brasil apresentava de fato uma conjuntura fiscal indesejável com grande parte da dívida indexada à moeda estrangeira e um alto grau de incerteza quanto ao rumo que seria dado as políticas econômicas com a iminência da vitoria de um candidato de esquerda nas eleições presidenciais.

Os resultados encontrados por Gadelha e Divino (2008) para economia brasileira no período de 1995 - 2005 indicam que não é possível validar as relações entre política fiscal e monetária definidas por Blanchard (2004). Os autores se respaldam na análise de causalidade para enfatizar que no período estudado a economia brasileira encontrou-se em um regime de dominância monetária.

A hipótese de dominância fiscal para economia brasileira no período de 1999 - 2006 também é refutada no trabalho de Aguiar (2007). Segundo a autora, as decisões da autoridade fiscal no Brasil não impõem limites à política monetária. Os resultados evidenciam uma preocupação da autoridade fiscal em garantir a estabilidade da razão DLSP/PIB.

Mendonça e Pires (2007) partiram dos argumentos teóricos contidos nos modelos de Giavazzi e Pagano (1990) e de Calvo e Guidotti (1990) e apresentaram evidências empíricas, por meio da aplicação de um modelo autoregressivo vetorial (VAR), para o caso brasileiro. As evidências encontradas mostraram que o prazo médio da dívida pública em mercado, assim como a razão dívida/ Produto Interno Bruto (PIB) e a estrutura de indexação, têm importância para a determinação da taxa de juros básica da economia. Nessas condições, os autores concluíram que a instância fiscal afeta a política monetária.

Fialho e Portugal (2004) procuraram identificar a predominância de um regime de dominância monetária ou fiscal no Brasil no período pós-real. Esta análise foi desenvolvida com base no modelo proposto por Canzoneri, Cumby e Diba (2000) que propõe uma relação entre as séries dívida pública/ PIB e superávit primário/PIB através da metodologia VAR. Esses concluíram que a coordenação macroeconômica entre as políticas monetária e fiscal no Brasil foi praticamente de caráter substituta em todo período analisado e com regime predominantemente monetário, segundo o pressuposto de políticas não-ricardianas da teoria fiscal do nível de preços.

O trabalho de Marques Júnior (2010) verificou a existência de dominância fiscal na economia brasileira no período de 2003 a 2008. O objetivo central do trabalho foi testar a hipótese defendida por Blanchard (2004), onde, segundo o autor, no período de 1999 a 2003 a economia brasileira viveu sob a vigên-

1 Exceto pelo artigo de Marques Júnior (2010). 
cia do tipo específico de dominância fiscal, onde as circunstâncias impostas pelas variáveis fiscais faziam com que uma política monetária restritiva não alcançasse os objetivos esperados, levando, no caso brasileiro, a resultados contrários.

Marques Junior (2010) esquadrinhou o mesmo caminho percorrido por Blanchard (2004) e verificou que há uma relação positiva entre dívida pública e o risco de default, sugerindo que, embora as circunstâncias fiscais tenham melhorado a dominância fiscal, continua existindo na economia brasileira no período de 2003 - 2008. Entretanto, o autor ressalta que seus resultados são significativamente menores do que os encontrados por Blanchard (2004). $\mathrm{O}$ autor ainda sugere que as reduções podem indicar que tal relação seja passageira, algo conjuntural que não deva ser mais verificado em períodos posteriores.

Embora os estudos sobre dominância fiscal no Brasil tenham certa uniformidade quanto aos resultados, estes não são ainda conclusivos quanto à temática, haja vista a existência de distintas metodologias e períodos a serem estudados. Neste trabalho o período da economia brasileira estudado é de 2003 a 2009 e a metodologia aplicada é um modelo vetor de correção de erros (VECM) que é apresentado na próxima seção.

\section{Procedimentos Metodológicos}

A abordagem empírica inicia-se pelas seguintes etapas: na primeira, aplica-se para cada série de tempo o teste de raiz unitária de Dickey e Fuller (1979), com o objetivo de identificar a estacionariedade (ou seja, presença ou não de raiz unitária). Na segunda etapa, pretende-se realizar o teste de co-integração de Johansen com a finalidade de verificar se as variáveis no sistema são co-integradas e se há algum vetor co-integrante.

Para o caso de as séries de tempo serem não estacionárias e apresentarem dinâmica em comum, pode-se especificar um modelo VAR mais completo denominado modelo vetor de correção de erros (VECM). Esse modelo tem o propósito de identificar uma relação de longo prazo entre as séries, assim como, procurar alguma relação de repasse entre as políticas monetária e fiscal no curto prazo. 


\subsection{Base de Dados}

- EMBI+: é um índice baseado nos bônus (títulos de dívida) emitidos pelos países emergentes. Mostra os retornos financeiros obtidos a cada dia por uma carteira selecionada de títulos desses países. Os pontos mostram a diferença entre a taxa de retorno dos títulos de países emergentes e a oferecida por títulos emitidos pelo Tesouro americano. Essa diferença é o spread, ou o spread soberano.

- Taxa de juros - Over / Selic (\% a.m.): corresponde a variação mensal do sistema eletrônico de liquidação e custódia, que é a média de remuneração dos títulos públicos federais negociados com os bancos e demais investidores institucionais.

- $\quad$ NFSP com desvalorização cambial (\% PIB) - Fluxo mensal corrente - Resultado nominal - Total - Governo Federal e Banco Central.

- Dívida Líquida do Setor Público (\% PIB) - Total - Governo Federal e Banco Central.

- Índice da taxa de câmbio efetiva real (IPCA) - Jun/1994=100.

\section{Resultados}

Nesta seção serão apresentados os resultados e discussões obtidos pelo modelo VECM relacionado à interação entre as políticas monetária e fiscal, no período de 2003 a 2009. Antes de estimar os modelos, foram realizados alguns testes preliminares, raiz unitária (Dickey-Fuller Aumentado - ADF) e co-integração (Johansen).

O teste aplicado para identificar a presença ou ausência de raiz unitária foi o de Dickey-Fuller Aumentado (ADF) ${ }^{2}$. A hipótese nula do teste de ADF é que as séries são não-estacionárias e podem ser representadas pelos modelos de passeio aleatório sem deslocamento, com deslocamento e com tendência e deslocamento. Por sua vez, a hipótese alternativa deste teste representa séries que apresentam caráter transitório na presença de choques exógenos.

2 É importante salientar que a análise do teste ADF é realizada em termos absolutos; $t_{\alpha}>t_{\text {critico }}$ representa que a série é estacionária. 
TABELA 1: TESTE DE RAIZ UNITÁRIA (DICKEY-FULLER AUMENTADO ADF) APLICADO NAS SÉRIES NFSP, SELIC, CÂMBIO, EMBI E DÍVIDA EM NÍVEL E $1^{\mathrm{a}}$ DIFERENÇA, NO PERÍODO DE 2003 A 2009.

\begin{tabular}{|c|c|c|c|c|c|c|c|}
\hline \multirow[t]{2}{*}{ Séries } & \multicolumn{2}{|c|}{$\begin{array}{l}\text { Modelo sem } \\
\text { intercepto e sem } \\
\text { tendência }\end{array}$} & \multicolumn{2}{|c|}{$\begin{array}{l}\text { Modelo com } \\
\text { intercepto e sem } \\
\text { tendência }\end{array}$} & \multicolumn{3}{|c|}{$\begin{array}{l}\text { Modelo com intercepto e } \\
\text { com tendência }\end{array}$} \\
\hline & $t$ nível & $t$ crítico & $t$ nível & $t$ crítico & $t$ nível & $t$ dif & $t$ crítico \\
\hline NFSP & $-3,36$ & $-1,94$ & $-8,14$ & $-2,86$ & $-8,15$ & - & $-3,41$ \\
\hline Selic & $-1,60$ & $-1,94$ & $-1,74$ & $-2,86$ & $-3,96$ & $-4,23$ & $-3,41$ \\
\hline Câmbio & $-2,53$ & $-1,94$ & $-1,78$ & $-2,86$ & $-3,13$ & $-7,28$ & $-3,41$ \\
\hline EMBI & $-1,16$ & $-1,94$ & $-2,99$ & $-2,86$ & $-4,53$ & $-9,56$ & $-3,41$ \\
\hline Dívida & $-1,30$ & $-1,94$ & $-2,97$ & $-2,86$ & $-2,97$ & $-6,88$ & $-3,41$ \\
\hline
\end{tabular}

Fonte: Elaboração própria.

Os resultados das estatísticas do teste Dickey-Fuller Aumentado (ADF), descritos na tabela 1, indicam que todas as séries são não estacionárias (com exceção da NFSP), de acordo com o nível de significância estatística de 5\%, ou seja, as séries são integradas de ordem I(1).

Uma análise informal utilizada para verificar se duas ou mais séries são co-integradas é dada pela análise gráfica. Apesar de ser um indicador, a análise gráfica não é suficiente para identificar se as séries apresentam uma tendência comum de longo prazo. Os gráficos abaixo mostram que, com exceção NFSP, todas as séries parecem compartilhar da mesma tendência.

\section{GRÁFICO 1: ÍNDICE DA TAXA DE CÂMBIO EFETIVA REAL}

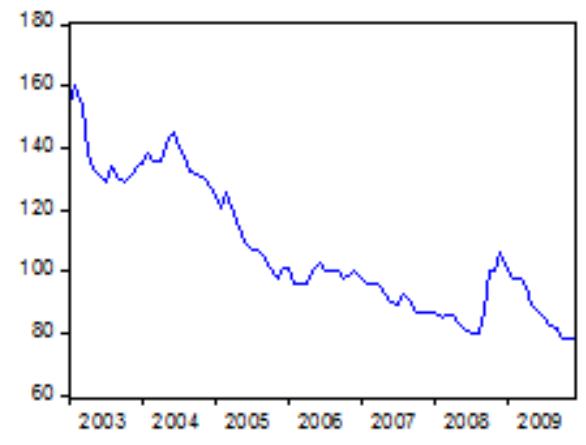

Fonte: Banco Central 


\section{GRÁFICO 2: DÍVIDA LÍQUIDA DO SETOR PÚBLICO}

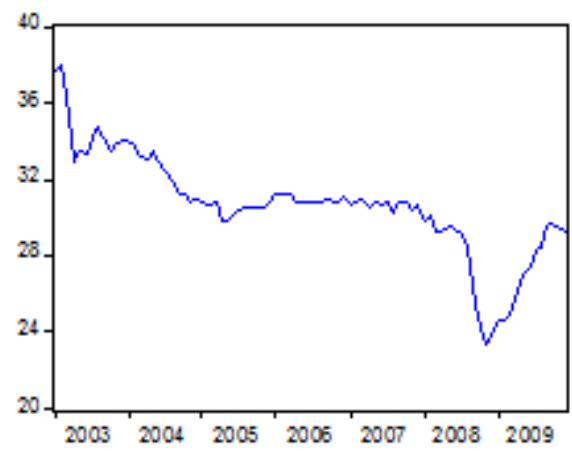

Fonte: Banco Central

GRÁFICO 3: EMERGING MARKETS BOND INDEX

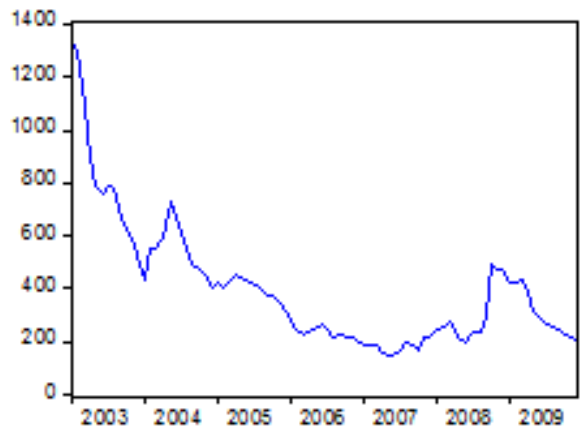

Fonte: Ipeadata

GRÁFICO 4: NECESSIDADE DE FINANCIAMENTO DO SETOR PÚBLICO

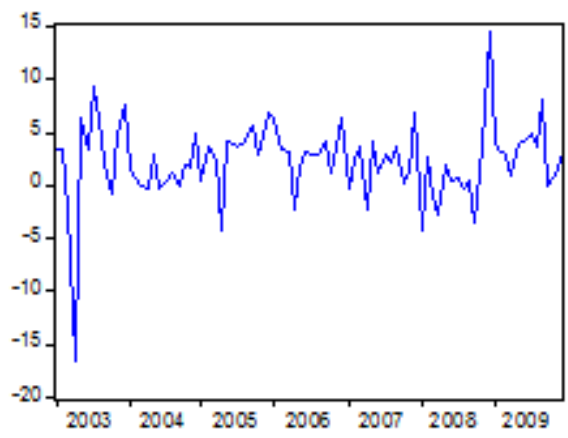

Fonte: Banco Central 


\section{GRÁFICO 5: SISTEMA EPECIAL DE LIQUIDAÇÃO E CUSTÓDIA (SELIC)}

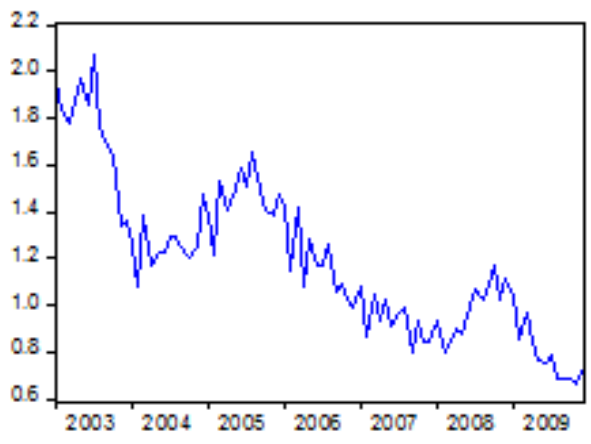

Fonte: Banco Central

A Tabela 2 apresenta o teste de co-integração de Johansen com tendência linear determinística.

TABELA 2: TESTE DE CO-INTEGRAÇÃO DE JOHANSEN

\begin{tabular}{lcccc}
\hline & Traço & Prob. & $\begin{array}{c}\text { Máx. Auto- } \\
\text { valor }\end{array}$ & Prob. \\
\hline Nenhum & 132,7 & 0,00 & 66,76 & 0,00 \\
1 Vetor & 65,98 & 0,00 & 41,03 & 0,00 \\
2 Vetores & 24,94 & 0,16 & 15,35 & 0,26 \\
3 Vetores & 9,596 & 0,31 & 6,694 & 0,52 \\
4 Vetores & 2,902 & 0,09 & 2,902 & 0,09 \\
\hline
\end{tabular}

Fonte: Elaboração própria.

Os resultados dos testes do traço e do máximo autovalor não rejeitam a hipótese de existência de pelo menos dois vetores de co-integração. Assim, é possível concluir que as séries apresentam uma tendência estocástica comum de longo prazo (co-integradas). A Tabela 3 representa os desequilíbrios de curto e longo prazo, obtidos por meio do modelo VEC. 
TABELA 3: MODELO DE CORREÇÃO DE ERROS (VECM), DINÂMICA DE CURTO E LONGO PRAZO

\begin{tabular}{|c|c|c|c|c|c|}
\hline & $\Delta$ cambio $_{t}$ & $\Delta$ divida $_{t}$ & $\Delta e m b i_{t}$ & $\Delta n f s p_{t}$ & $\Delta$ selic $_{t}$ \\
\hline \multirow{2}{*}{$\begin{array}{l}\text { Vetor de Co- } \\
\text {-integração }\end{array}$} & $-0,12^{*}$ & $-0,02^{*}$ & $5,39^{*}$ & $-0,12^{*}$ & 0,00 \\
\hline & $(0,02)$ & $(0,00)$ & $(0,72)$ & $(0,03)$ & $(0,00)$ \\
\hline \multirow[t]{2}{*}{$\Delta$ cambio $_{t-1}$} & $0,24^{*}$ & $-0,05^{*}$ & 0,26 & $-0,22^{* *}$ & $-0,01$ \\
\hline & $(0,02)$ & $(0,02)$ & $(2,78)$ & $(0,11)$ & $(0,01)$ \\
\hline \multirow[t]{2}{*}{$\Delta$ cambio $_{t-2}$} & $-0,11$ & $-0,01$ & 0,84 & $-0,07$ & 0,00 \\
\hline & $(0,11)$ & $(0,02)$ & $(2,85)$ & $(0,12)$ & $(0,01)$ \\
\hline \multirow[t]{2}{*}{$\Delta$ divida $_{t-1}$} & $-3,11^{*}$ & 0,21 & $-29,01$ & $-2,75^{*}$ & $-0,09 *$ \\
\hline & $(0,93)$ & $(0,17)$ & $(23,64)$ & $(1,01)$ & $(0,03)$ \\
\hline \multirow[t]{2}{*}{$\Delta d i v i d a_{t-2}$} & $-0,36^{*}$ & $-0,13$ & $59,40^{*}$ & $-1,44$ & $0,06 * *$ \\
\hline & $(1,03)$ & $(0,18)$ & $(26,11)$ & $(1,12)$ & $(0,03)$ \\
\hline \multirow[t]{2}{*}{$\Delta e m b i_{t-1}$} & $-0,01^{*}$ & 0,00 & 0,04 & 0,00 & 0,00 \\
\hline & $(0,01)$ & $(0,42)$ & $(0,12)$ & $(0,01)$ & $(0,00)$ \\
\hline \multirow[t]{2}{*}{$\Delta e m b i_{t-2}$} & $-0,01$ & $\mathrm{O}, \mathrm{OO}$ & $0,20^{* *}$ & 0,00 & 0,00 \\
\hline & $(0,01)$ & $(0,01)$ & $(0,11)$ & $(0,01)$ & $(0,00)$ \\
\hline \multirow[t]{2}{*}{$\Delta n f s p_{t-1}$} & $-0,02$ & 0,01 & $9,03^{*}$ & $-0,47^{*}$ & $0,02^{*}$ \\
\hline & $(0,09)$ & $(0,03)$ & $(3,81)$ & $(0,16)$ & $(0,01)$ \\
\hline \multirow[t]{2}{*}{$\Delta n f s p_{t-2}$} & $-0,15$ & $\mathrm{O}, \mathrm{O} 1$ & 2,07 & $-0,16^{* *}$ & 0,00 \\
\hline & $(0,09)$ & $(0,02)$ & $(2,30)$ & $(0,01)$ & $(0,01)$ \\
\hline \multirow[t]{2}{*}{$\Delta$ selic $_{t-1}$} & $-2,08$ & 0,13 & $-104,79$ & 1,28 & $-0,67^{*}$ \\
\hline & $(3,43)$ & $(0,62)$ & $(86,98)$ & $(3,73)$ & $(0,11)$ \\
\hline \multirow[t]{2}{*}{$\Delta$ selic $_{t-2}$} & $-0,49^{*}$ & 0,58 & $-80,68$ & $9,85^{*}$ & $-0,13$ \\
\hline & $(3,35)$ & $(0,60)$ & $(84,84)$ & $(3,64)$ & $(0,11)$ \\
\hline
\end{tabular}

Fonte: Elaboração Própria.

Nota: * significativo $5 \% ;{ }^{* *}$ significativo $10 \%$.

Os resultados mostram que as políticas monetária e fiscal estão interligadas, como apontam os coeficientes de ajuste de desequilíbrios longo prazo (vetor de co-integração), onde choques de longo prazo são incorporados à dinâmica de longo prazo como fator de redução, no caso do câmbio, dívida e NFSP e aumento no caso do EMBI, sendo esses percebidos 
como duradouros.

Quanto aos choques de curto prazo, observa-se que a taxa de câmbio é unilateralmente influenciada (negativamente) pelo pela taxa de juros, ou seja, elevações na taxa de juros provocam um processo de apreciação do câmbio. Este resultado corrobora a hipótese da teoria convencional, onde para o período estudado, um aumento na taxa de juros amplia a atratividade dos títulos públicos causando uma maior entrada de capitais no país.

A taxa de câmbio também é unilateralmente influenciada (negativamente) pelo prêmio de risco. Embora esta influência seja mínima, ela demonstra-se contrária ao definido por Blanchard (2004), onde o prêmio pelo risco deveria depreciar e não apreciar a taxa de câmbio.

Ao mesmo tempo, temos que a NFSP é unilateralmente influenciada (negativamente) pela dívida pública. Este resultado demonstra que a geração de déficit leva em consideração a estabilidade da relação dívida/PIB. Ou seja, corrobora com definição de dominância monetária estabelecida por Sargent e Wallace (1981).

Observa-se que a NFSP afeta o spread do EMBI e a taxa Selic. Segundo Gadelha e Divino (2008), isso mostra que há ganhos de credibilidade da política fiscal, a qual também não está condicionada a mudanças na percepção de riscos dos agentes internacionais.

Para o caso de um aumento na razão dívida/PIB não acompanhado pelo aumento no superávit primário, percebe-se um aumento no estoque da dívida, o que implica aumento no prêmio de risco e depreciação cambial. Isto poderia sinalizar a existência de dominância fiscal, entretanto esta relação não é confirmada pelas demais análises.

A idéia de dominância fiscal é claramente refutada quando observamos que a Taxa Selic e o prêmio pelo risco (EMBI) não possuem nenhuma relação causal. Assim, a idéia de que a elevação na Taxa Selic precede elevações no prêmio pelo risco não encontra evidência empírica para período estudado.

A taxa Selic afeta a taxa real de câmbio e isso mostra que Banco Central está reagindo à volatilidade da taxa de câmbio real por meio do instrumento de política monetária. Apesar de a taxa Selic não ter afetado a razão dívida/ PIB, essa impactou positivamente a NFSP. Isso pode ser explicado pelo fato de que cerca $30 \%$ da dívida pública ser indexada a taxa Selic, pois alterações na Selic afetam a dívida pública e para manter a dívida solvente, deve haver aumento no superávit primário.

Portanto, os resultados verificados na tabela 3 demonstram que para a economia brasileira, no período estudado, há um efeito de dominância monetária. De modo geral, observa-se que os resultados encontrados por Blanchard (2004) não encontram respaldo empírico para sua validação. 


\section{Considerações finais}

A análise empírica sugere que, para o período de 2003 a 2009, a economia brasileira apresenta uma relação de dominância monetária. A visão tradicional de regime de dominância monetária é aquela em que a autoridade fiscal passiva gera um superávit primário compatível com a estabilização da relação dívida/PIB. Desse modo a autoridade monetária ativa não é forçada a monetizar a dívida pública, mantendo o controle do nível de preços determinado pela demanda e oferta de moeda.

A análise mostrou que acréscimos na taxa de juros não influenciam o prêmio de risco, ou seja, os agentes não mudam suas avaliações quanto ao risco de default por conta de variações na taxa de juros o que implica a validação da teoria tradicional que afirma que um aumento na taxa de juros leva a uma maior atratividade dos títulos públicos, resultando em um influxo de capital. Desta forma, a política monetária é eficaz em seu objetivo de controle do nível de preço.

Pelos resultados encontrados, não foi possível identificar de forma clara quais as influências das variáveis analisadas sobre o prêmio de risco, o que leva a interpretá-la como uma variável exógena. Resultado contrário ao previsto por Blanchard (2004), entretanto segue os mesmos indícios apontados por Aguiar (2007).

Observa-se de forma geral que as alterações na economia brasileira se deram de forma equilibrada, mantendo-se a independência da política monetária em relação à política fiscal. Os esforços fiscais em busca de um maior crescimento da economia não foram contraproducentes aos objetivos de controle do nível de preço. O que demonstra de certa forma, que o canal de transmissão do controle de preços via apreciação do câmbio é mais eficaz do que o canal de contração da demanda agregada.

Outra verificação importante é a validação dos indícios apontados no trabalho Marques Junior (2010), que embora tenha verificado sinais de dominância fiscal, ressaltou a transitividade desta relação na economia brasileira.

Esperava-se que com a adoção de uma política fiscal mais expansiva, como a que se deu no segundo mandato do governo Lula, que as variáveis fiscais fossem ter uma maior influência nas variáveis monetárias. Entretanto, comparando os resultados do trabalho com os pressupostos do artigo de Blanchard (2004), fica demonstrado que não há evidências empíricas que corroborem a existência de dominância fiscal para o período estudado. 


\section{Referências}

Aguiar, Marianne Thamm de (2007). Dominância fiscal e a regra de reação fiscal: uma análise empírica para o Brasil. Tese de Doutorado. Universidade de São Paulo, 2007.

Blanchard, O. (2004). "Fiscal dominance and inflation targeting: lesson from Brazil". NBER WP n⿳0 10389.

Calvo, G.; Guidotti, P. (1990). "Indexation and maturity of government bonds: an exploratory model”. In: Dorbbusch, R. ; Draghi, M. Public Debt Management : theory and history. Cambridge: Cambridge University Press, pp. 52-93.

Campbell, J. Y. E Perron, P. (1991). "Pitfalls and opportunities: what macroeconomics should know about unit roots". In: Blanchard, O. J.; Fischer, S. (Org.). NBER Macroeconomics Annual, n. 6. Cambridge: MIT Press.

Canzoneri, Matthew; Cumby, Robert; Diba, Bezhad (2000). Is the Price Level Determined by the Needs of Fiscal Solvency? Forthcoming American Economic Review, 2000.

Dickey, D. A.; Fuller, W. A. (1979). "Distribution of the estimators for autoregressive time series with unit root”. Journal of the American Statistical Association, $v$. 74 (336).

Engle, R. F.; Granger, C. W. J. (1987). "Co-integration and error correction: representation, estimation and testing”. Econometrica, v. 55 (2), pp. 251-276.

Fialho, Marcelo Ladeira; Portugal, Marcelo Savino (2005). Monetary and fiscal policy interactions in Brazil: an application of the fiscal theory of the price level. Estudos Econômicos (São Paulo), v. 35, n. 4, p. 657-685, 2005.

Fialho, M. L.; Portugal, M. S. (2005). "Monetary and fiscal policy interactions in Brazil: an application to the fiscal theory of the price level". Estudos Econômicos, v. 35 (4), pp. $657-685$.

Giavazzi, F. ; Pagano, M. (1990). "Confidence crises and public debt management”. In: Dorbbusch, R. ; Draghi, M. (Ed.). Public debt management: theory and history. Cambridge: Cambridge University Press.

Gadelha, Sérgio Ricardo de Brito; Divino, José Angelo. Dominância fiscal ou dominância monetária no Brasil? Uma análise de causalidade. Economia Aplicada, v. 12, n. 4, p. 659-675, 2008.

Johansen, S. E Juselius, K. (1990). "Maximum likelihood estimation and inference on cointegration with applications for the demand for money". Oxford Bulletin of Economics and Statistics, 52, pp. 169-210.

Johansen, S. (1991). "Estimation and hypothesis test of cointegration vectors in Gaussian vector autoregressive models”. Econometrica, v. 59, pp. 1551-1580.

Marques Junior, K. (2010). "Há dominância fiscal na economia brasileria? Uma análise empírica para o período do governo Lula.” Indicadores econômicos. FEE, Porto Alegre.

Mendonça, H. F. (2004). “A importância do tamanho, do prazo médio, e da estrutura de vencimento para a administração da dívida pública: uma análise a partir dos modelos de Giavazzi-Pagano (1990) e de Calvo-Guidotti (1990)”. Economia e Sociedade, v. 13 (1), pp. 1-19. 
Mendonça, Helder Ferreira; PIRES, M. C. C (2007). A interdependência fiscalmonetária: uma análise da importância da suavização da taxa de juros e do gerenciamento da dívida pública sobre o equilíbrio fiscal. Cadernos de Finanças Públicas-ESAF, n. 8, p. 101-122, 2007.

Sargent, T. J.; Wallace, N (1981). Some unpleasant monetarist arithmetic. Quarterly Review, Federal Reserve Bank of Minneapolis, v. 5, n. 3, p. 1-17, 1981.

\section{ANEXO}

Ao se comparar dois ou mais modelos o critério de seleção será dado pelo modelo que apresentar o menor valor de AIC e SBC. O critério SBC é mais rigoroso quanto à incorporação de regressores que o critério AIC, assim a ordem do modelo foi obtido de acordo com esse critério.

\begin{tabular}{ccc}
\hline & & VECM \\
\hline Defasagens & Akaike & Schwartz \\
\hline 2 & 22,154 & 23,912 \\
3 & 22,253 & 24,704 \\
4 & 22,241 & 25,393 \\
5 & 21,984 & 25,846 \\
6 & 21,283 & 25,866 \\
7 & 20,570 & 25,883 \\
8 & 20,500 & 26,553 \\
9 & 19,683 & 26,486 \\
10 & 18,976 & 25,539 \\
11 & 18,381 & 26,715 \\
12 & 17,383 & 26,498 \\
\hline
\end{tabular}

Fonte: Elaboração própria. 